\title{
Hydroamination Reactions by Metal Triflates: Brønsted Acid vs. Metal Catalysis?
}

\author{
Jason G. Taylor Luis A. Adrio and King Kuok (Mimi) Hii* \\ Received (in XXX, XXX) Xth XXXXXXXXX 200X, Accepted Xth XXXXXXXXX 200X \\ ${ }_{5}$ First published on the web Xth $X X X X X X X X X 200 X$ \\ DOI: $10.1039 / b 000000 x$
}

Catalytic hydroamination reactions involving the addition of carboxamide, carbamates and sulfonamides to unactivated $\mathrm{C}=\mathrm{C}$ bonds are briefly reviewed. Development in this field of catalytic research is briefly charted, followed by a discussion of possible mechanisms, including arguments to support the operation of both metal and Brønsted acid catalysis in these systems.

${ }_{10}$ Future developments in the area are summarised.

\section{Introduction}

$$
\mathrm{R}^{1} \searrow \mathrm{R}^{2}+\mathrm{H}-\mathrm{NR}^{3}{ }_{2} \stackrel{\text { catalyst }}{\longrightarrow} \mathrm{R}^{1} \overbrace{\mathrm{R}^{2}}^{\mathrm{N}_{2}}+\mathrm{R}^{1} \overbrace{\mathrm{NR}^{3}{ }_{2}}^{\mathrm{R}^{2}}
$$

Scheme 1 Hydroamination reactions

15 Direct addition of $\mathrm{N}-\mathrm{H}$ bonds across a $\mathrm{C}=\mathrm{C}$ bond, also known as the hydroamination reaction, produces highly valuable nitrogen-containing compounds from readily available precursors (Scheme 1). As the reaction does not generate any waste, research in this area of catalytic chemistry has 20 intensified over the last decade, ${ }^{1}$ driven by the increasing demand for more efficient and green processes, particularly for the production of fine chemicals and pharmaceutical compounds. $^{2}$
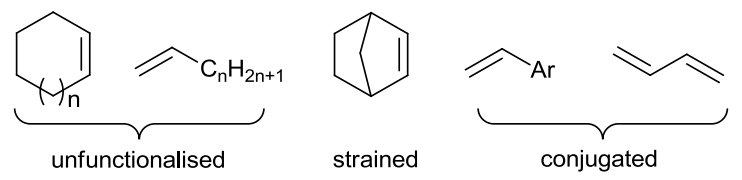

Fig. 1 Types of 'unactivated' alkene substrates.

With the exception of $a z a$-Michael reactions, where amines add spontaneously to electron-deficient alkenes in protic solvents, ${ }^{3}$ most hydroamination reactions have very high activation energies, particularly if it involves reactions of 30 unactivated alkenes. In these cases, unfavourable kinetic barriers can be overcome by the use of catalysts.

Strictly speaking, 'unactivated' alkenes refer to unfunctionalised $\mathrm{C}=\mathrm{C}$ bonds, i.e. cyclic or acyclic alkenes with $\mathrm{H}$ or alkyl substituents, although more reactive systems 35 such as the strained norbornene and conjugated alkenes (vinylarenes and 1,3-dienes) are often included in this category (fig. 1). ${ }^{4}$

Certain hydroamination reactions, particularly intramolecular cyclisation of aminoalkenes, can be catalysed 40 by using alkali (earth) metal complexes such as $n$-BuLi and metal amides. ${ }^{5,6}$ As the application of such highly basic entities is not always desirable or practical, much research in the area has been directed towards the development of transition metal catalysts. Two mechanisms are often 45 suggested for these, where $\mathrm{C}-\mathrm{N}$ formation is triggered by the activation of either the $\mathrm{N}-\mathrm{H}$ or $\mathrm{C}=\mathrm{C}$ moiety (Scheme 2).
Lanthanides/early metal complexes generally favour route A, where reactions proceed by activation of the $\mathrm{N}-\mathrm{H}$ bond, followed by insertion of the $\mathrm{C}=\mathrm{C}$ across the resultant $\mathrm{M}-\mathrm{N}$ 50 bond (when $\mathrm{M}=\mathrm{Ln})^{7}$ or, if a primary amine is used, a metalimido complex can be formed (when $\mathrm{M}=$ group 4 transition metal) ${ }^{8,} 9$ in which case, bond formation between $\mathrm{M}=\mathrm{N}$ and $\mathrm{C}=\mathrm{C}$ can occur via a $[2+2]$ cycloaddition. Conversely, late transition metal catalysts (e.g. $\mathrm{Rh}, \mathrm{Pd}, \mathrm{Pt}$ ) favour $\pi$ 55 coordination of the $\mathrm{C}=\mathrm{C}$ bond, activating it towards exometallic attack of the nucleophilic amine (Scheme 2, route B). ${ }^{10-12}$ In both of these routes, the turnover step requires the protonolysis of the alkyl-M bond. For most addition of nucleophilic primary or secondary alkylamines and anilines, 60 reaction mechanisms are fairly well established, including the isolation of catalytically-viable intermediates, theoretical studies $^{13}$ and enantioselective examples, which have been described in a previous Perspective. ${ }^{14}$

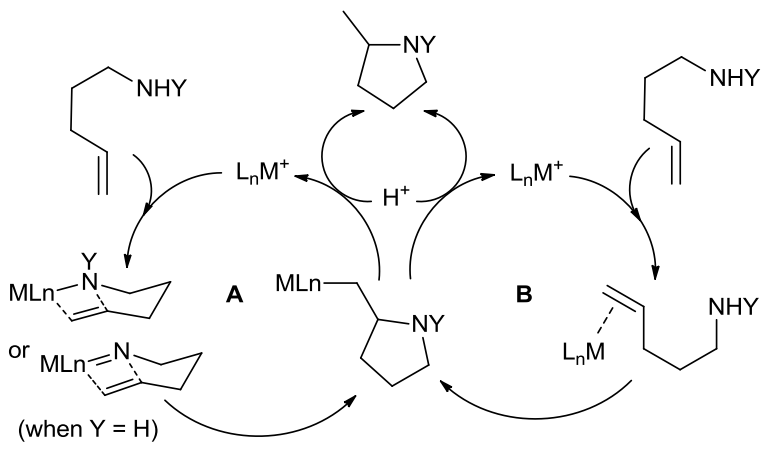

65 Scheme 2 General mechanisms for metal-catalysed hydroamination reactions (illustrated for intramolecular reactions).

In recent years, there has been significant debate over the existence of alternative reaction mechanisms, particularly for the addition of non-nucleophilic (also referred as 'non-basic') 70 amines, exemplified by carboxamides, sulfonamides and carbamates, to unactivated alkenes. This type of hydroamination reaction was first reported in 2005 by Qian and Widenhoefer, ${ }^{15}$ where the addition of carboxamides to vinylarenes proceeded in mesitylene at $140{ }^{\circ} \mathrm{C}$, by using a 75 platinum catalyst generated from a mixture of $\left[\mathrm{PtCl}_{2}\left(\mathrm{H}_{2} \mathrm{C}=\mathrm{CH}_{2}\right)\right]_{2}(2.5 \mathrm{~mol} \%)$ and $\left(4-\mathrm{CF}_{3} \mathrm{C}_{6} \mathrm{H}_{4}\right)_{3} \mathrm{P}(5 \mathrm{~mol} \%)$. This was followed closely by a report by Tilley and coworkers, where (COD)Pt(OTf $)_{2}$ at $10 \mathrm{~mol} \%$ effected the 
addition of sulfonamides and aromatic amines to cyclic and acyclic alkenes at a much lower reaction temperature (75-90 $\left.{ }^{\circ} \mathrm{C}\right) .{ }^{16}$

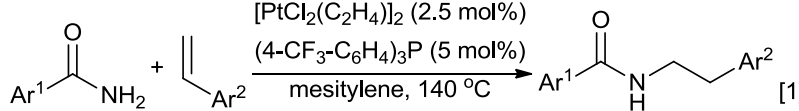

$$
\begin{aligned}
& \mathrm{Ts}-\mathrm{NH}_{2}+\llbracket \underset{\substack{1,2 \text {-dichlorobenzene, } \\
75-90^{\circ} \mathrm{C}}}{\stackrel{\left[\mathrm{Pt}(\mathrm{COD})(\mathrm{OTf})_{2}\right](10 \mathrm{~mol} \%)}{\longrightarrow}}
\end{aligned}
$$

5 Scheme 3 Pt-catalysed hydroamination of unactivated alkenes by nonnucleophilic N-H bonds.

The use of group 11 coinage metal complexes for these reactions emerged shortly (Scheme 4), with reports of interand intra-molecular addition of sulfonamides and carbamates 10 to alkenes ${ }^{17}$ and 1,3-dienes ${ }^{18}$ under mild reaction conditions, using a cationic gold(I) complex generated from $5 \mathrm{~mol} \%$ of $\mathrm{Ph}_{3} \mathrm{PAuCl} / \mathrm{AgOTf}{ }^{19}$ In these studies, catalytic activity was attributed to $\pi$-activation of the $\mathrm{C}=\mathrm{C}$ bond by the metal (as shown by route B in Scheme 2).

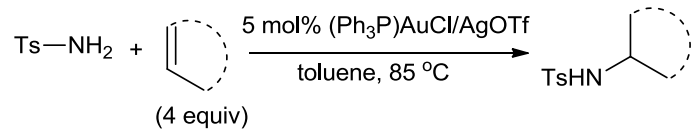

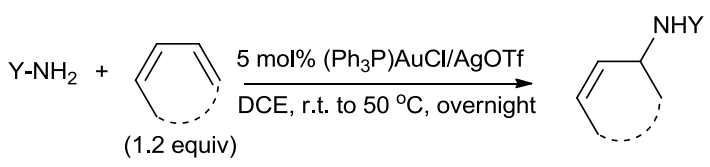

$\mathrm{YNH}_{2}=\mathrm{TsNH}_{2}, \mathrm{RCO}_{2} \mathrm{NH}_{2}$

Scheme 4 Hydroamination of unactivated catalysed by cationic gold(I) complexes.

Around the same time, work from our laboratory discovered the use of $\mathrm{Cu}(\mathrm{OTf})_{2}$ for the $\mathrm{O}-\mathrm{H}$ addition of acids 20 and alcohols to norbornene, ${ }^{20}$ which was later extended to the addition of sulfonamides. Furthermore, in the presence of a diphosphine ligand, addition to vinylarenes and 1,3-dienes can also be effected under similar reaction conditions (Scheme $5) .^{21}$

$$
\begin{aligned}
& \mathrm{Ar}^{2} \mathrm{SO}_{2} \mathrm{NH}_{2}+\underset{\text { dioxane, } 85^{\circ} \mathrm{C}}{\frac{10 \mathrm{~mol} \% \mathrm{Cu}(\mathrm{OTf})_{2}}{\longrightarrow}} \mathrm{NHSO}_{2} \mathrm{Ar}^{2} \\
& \mathrm{TsNH}_{2}+\square \frac{5 \mathrm{~mol} \% \mathrm{Cu}(\mathrm{OTf})_{2} / \mathrm{dppe}}{\text { dioxane, } 55^{\circ} \mathrm{C}} \\
& 92 \% \\
& \mathrm{Ar}^{2} \mathrm{SO}_{2} \mathrm{NH}_{2}+\|_{\mathrm{Ar}^{1}} \underset{75^{\circ} \mathrm{C} \text {, dioxane }}{\stackrel{\mathrm{Cu}(\mathrm{OTf})_{2} / \mathrm{BINAP}}{\longrightarrow}} \mathrm{Ar}^{1} \stackrel{\mathrm{NHSO}_{2} \mathrm{Ar}^{2}}{\mathrm{CH}_{3}} \\
& \text { up to } 97 \% \\
& \mathrm{Ar}_{\mathrm{CH}_{3}}^{1} \overbrace{1}^{\mathrm{Ar}^{1}} \\
& 1
\end{aligned}
$$

25

Scheme 5 Copper(II) catalysed addition of $\mathrm{TsNH}_{2}$ to unactivated alkenes.

Given that copper(II) is not as $\pi$-acidic as gold(I), ${ }^{22}$ we speculated that an alternative mechanism was in operation. This was supported by a series of observations made during 30 the study (reactions between $\mathrm{TsNH}_{2}$ and styrene):

1. The product yield was enhanced by increasing the amount of sulfonamide, but not by increasing the amount of styrene. Thus, the alkene is unlikely to be involved in the rate-limiting step.

352 . In cases where the reaction is slow, the major byproduct of the reaction is compound $\mathbf{1}$, a styrene dimer.

3. The reaction was suppressed by the presence of noncoordinating bases such as $\mathrm{CuCO}_{3}$ and $\mathrm{K}_{2} \mathrm{CO}_{3}(10 \mathrm{~mol} \%)$, suggesting the involvement of Brønsted acid.

404 . In the absence of sulfonamide, $\mathrm{Cu}(\mathrm{OTf})_{2}$ or triflic acid catalysed the conversion of styrene to the dimer $\mathbf{1}$ at 75 and $85{ }^{\circ} \mathrm{C}$, respectively.

5. Using $20 \mathrm{~mol} \%$ of $\mathrm{TfOH}$ as catalyst, the reaction between $\mathrm{TsNH}_{2}$ and styrene led to a very low yield of the expected

45 product and $\mathbf{1}$ (14\% and $15 \%$, respectively), the rest of the reaction mixture is composed of styrene oligomer/polymer.

Based on these observations, we postulated a catalytic cycle 50 where ligand metathesis between the metal complex and sulfonamide generates triflic acid. This protonates the alkene to produce a stable carbocation intermediate (I), which undergoes $\mathrm{C}-\mathrm{N}$ bond formation with the copper-amide complex II to give the product (Scheme 6). Where the ${ }_{55}$ reaction between $\mathbf{I}$ and $\mathbf{I I}$ is slow, competitive reaction of the carbocation and styrene occurs to give the dimer 1 . Subsequently, similar reaction mechanisms had been proposed for addition of toluenesulfonamide to norbornene catalysed by [(COD)Pt(OTf $\left.)_{2}\right]$ (Scheme 3, equation 2), ${ }^{23}$ and also for the 60 addition of aniline to norbornene by non-triflate based Lewis acids. $^{24}$

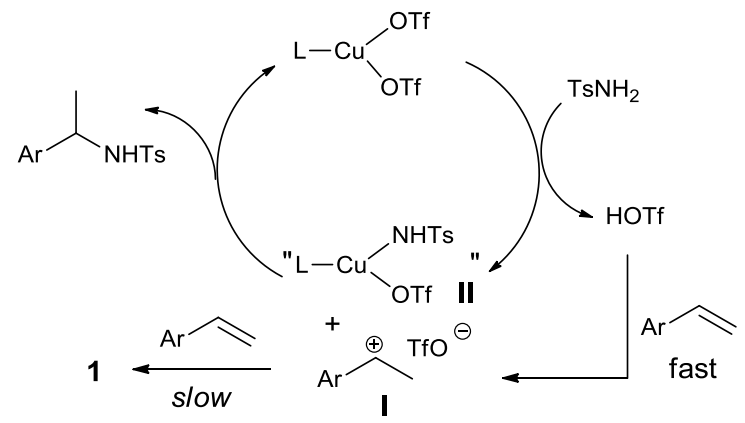

Scheme 6 Proposed mechanism for $\mathrm{Cu}(\mathrm{OTf})_{2}$-diphosphine catalysed hydroamination reaction. ${ }^{21}$

65 Following our publication, separate reports by Hartwig ${ }^{25}$ and $\mathrm{He}^{26}$ demonstrated that the use of triflic acid alone is effective for intermolecular addition of sulfonamides and carbamates to norbornene, vinylarenes and 1,3-dienes. The key to success is to employ a low catalyst loading (1-5 mol\%). 70 In agreement with our earlier results, low yields of the product were obtained at a higher loading of the acid (10-20 mol\%), due to competitive reactions to yield unspecified products (described as a series of isomeric products from the combination of two alkenes). By drawing parallels between 
product yields and distribution afforded by HOTf and metal triflate complexes, it was suggested that the latter are merely serving as precatalysts for the formation of a protic acid catalyst. $^{25}$

5 Formation of Brønsted acids by cation hydrolysis is a welldocumented process. ${ }^{27}$ However, there remained substantial differences in the observed catalyst activity between cationic gold(I) complexes and HOTf, which cannot be explained by a single mechanism. ${ }^{26}$ Also, the formation of $\left(\mathrm{Ph}_{3} \mathrm{P}\right)$ AuNHTs 10 and triflic acid was not observed by NMR experiments. ${ }^{17}$ For reactions catalysed by copper(II) complexes, there are several instances where differences can be observed (Table 1). ${ }^{28}$ For example, while triflic acid catalysed the addition of benzamide to styrene (entry 1) and toluenesulfonamide to 15 cyclohexene and cyclooctene (entries 3 and 6), Au catalyst has been shown to be better (entry 4) or comparable (entry 7) in two of these cases. In comparison, $\mathrm{Cu}(\mathrm{OTf})_{2}$-dppe was not productive under the same conditions (entries 2, 5 and 8). On the other hand, a higher product yield was afforded by the 20 copper catalyst than triflic acid, for the addition of $\mathrm{TsNH}_{2}$ to 1,3-cyclohexadiene, but only in the presence of dppe ligand (entries 9- 11).

Table 1 Comparison of catalytic activity of triflic acid, $\mathrm{Au}$ and $\mathrm{Cu}$ catalysts. $^{\mathrm{a}}$

\begin{tabular}{|c|c|c|c|c|}
\hline Entry & Reactants & Product & Catalyst $^{b}$ & Yield/\% \\
\hline $\begin{array}{l}1 \\
2\end{array}$ & $\mathrm{BzNH}_{2}$ & $\mathrm{NHBz}$ & $\begin{array}{c}\text { TfOH } \\
\mathrm{Cu}(\mathrm{OTf})_{2} / \mathrm{dppe}\end{array}$ & $\begin{array}{l}88^{25} \\
\mathrm{NR}\end{array}$ \\
\hline $\begin{array}{l}3 \\
4 \\
5\end{array}$ & $\mathrm{TsNH}_{2}$ & & $\begin{array}{c}\text { TfOH } \\
\mathrm{Ph}_{3} \mathrm{PAuOTf} \\
\mathrm{Cu}(\mathrm{OTf})_{2} / \text { dppe }\end{array}$ & $\begin{array}{l}58^{25} \\
90^{17} \\
\mathrm{NR}\end{array}$ \\
\hline $\begin{array}{l}6 \\
7 \\
8\end{array}$ & $\mathrm{TsNH}_{2}$ & & $\begin{array}{c}\text { TfOH } \\
\mathrm{Ph}_{3} \mathrm{PAuOTf} \\
\mathrm{Cu}(\mathrm{OTf})_{2} / \text { dppe }\end{array}$ & $\begin{array}{l}88 \\
83^{17} \\
N R\end{array}$ \\
\hline $\begin{array}{c}9 \\
10 \\
11\end{array}$ & $\mathrm{TsNH}_{2}$ & & $\begin{array}{c}\mathrm{TfOH} \\
\mathrm{Cu}(\mathrm{OTf})_{2} / \text { dppe } \\
\mathrm{Cu}(\mathrm{OTf})_{2}\end{array}$ & $\begin{array}{c}63^{25} \\
92 \\
3\end{array}$ \\
\hline
\end{tabular}

${ }_{25}{ }^{a}$ Reaction conditions: Dioxane, $100{ }^{\circ} \mathrm{C}, 24 \mathrm{~h}$ (Entries 1 and 2); toluene, 80-85 ${ }^{\circ} \mathrm{C}, 18 \mathrm{~h}$ (entries 3-8); Dioxane, 50-55 ${ }^{\circ} \mathrm{C}, 18 \mathrm{~h}$ (entries 9-11). ${ }^{b} 1$ $\mathrm{mol} \% \mathrm{TfOH}$ or $5 \mathrm{~mol} \% \mathrm{Cu}(\mathrm{OTf})_{2} / \mathrm{dppe}$ or $10 \mathrm{~mol} \% \mathrm{Cu}(\mathrm{OTf})_{2}$, or $5 \mathrm{~mol} \%$ $\mathrm{Ph}_{3} \mathrm{PAuOTf}$, generated from a mixture of $\mathrm{Ph}_{3} \mathrm{PAuCl} / \mathrm{AgOTf}$.

30 The ligand effect was further supported by an experiment, whereby the configurational stability of optically pure $(S)-N$ (1-phenylethyl)toluenesulfonamide, $(S)$-2, was monitored in the presence of $\mathrm{Cu}(\mathrm{OTf})_{2}$, with and without added rac-BINAP (Scheme 7). ${ }^{21}$ In the absence of added phosphine, the presence 35 of $10 \mathrm{~mol} \% \mathrm{Cu}(\mathrm{OTf})_{2}$ did not lead to any observable changes in the stereochemical integrity of the sulfonamide. In contrast, an erosion of the enantiopurity to $84 \%$ ee was observed at 5 mol\% of $\mathrm{Cu}(\mathrm{OTf})_{2}$-BINAP, clearly indicating a lower energy barrier in the presence of the ligand.

40 Furthermore, catalytic activity is not exclusive to metal triflate complexes; as shown by reports of other Lewis acidic metal catalysts for these processes, e.g. $\mathrm{InBr}_{3}{ }^{29}$ and $\mathrm{FeCl}_{3},{ }^{30}$ although they were employed at higher catalytic loadings (10$20 \mathrm{~mol} \%)$ and reaction temperatures $\left(120^{\circ} \mathrm{C}\right)$. Conversely,
45 solid acids e.g. $\mathrm{H}^{+}$exchanged montmorillonite ${ }^{31}$ and silicotungstic acid ${ }^{32}$ have also been reported to catalyse the addition of amides, sulfonamides and carbamates to cyclic and acyclic alkenes, vinylarenes and 1,3-hexadiene.<smiles>C[C@H]([NH3+])c1ccccc1</smiles>

(S)-2

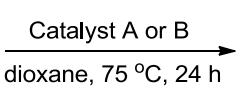

Catalyst A: $10 \mathrm{~mol} \% \mathrm{Cu}(\mathrm{OTf})_{2}$, no racemisation

Catalyst B: 5 mol\% Cu(OTf) 2,5 mol\% BINAP, $84 \%$ ee
50 Scheme 7 Ligand effect in the $\mathrm{Cu}$-mediated racemisation of an optically pure toluenesulfonamide.

Undoubtedly, Brønsted acid catalysis can be effective for the hydroamination reactions of unactivated alkenes. However, there is a growing body of evidence to suggest that 55 metal-catalysed processes cannot be ruled out completely. For example, recent theoretical calculations support the participation of the metal in the gold(I)-phosphine-catalysed hydroamination of 1,3 -dienes. ${ }^{33}$ In this study, DFT calculations suggest that the generation of a triflic acid by the 60 coordination of carbamate to the cationic gold(I) complex is energetically less favourable than the coordination of diene (the counteranion was found to have an important effect in the protonolysis step by acting as a proton shuffle).

Perhaps a more convincing case for metal-catalysed process 65 is the attainment of enantioselectivity. Asymmetric hydroamination reactions of unactivated alkenes have been limited almost exclusively to intramolecular cyclisation of aminoalkenes, ${ }^{1,14}$ with some limited intermolecular examples involving the addition of anilines to norbornene and styrene, 70 catalysed by iridium $^{34}$ and palladium, ${ }^{35}$ respectively. Reactions involving non-nucleophilic amines are particularly challenging, as several of these reactions can be reversible, ${ }^{15,21,36}$ so the attainment of high ee's is disfavoured by thermodynamics. ${ }^{34}$ In this respect, a significant 75 breakthrough has been achieved recently by Widenhoefer: ${ }^{37}$ using a mixture of $[(S)-3](\mathrm{AuCl})_{2}(2.5 \mathrm{~mol} \%)$ and $\operatorname{AgOTf}(5$ mol \%), reactions of 1 -alkenes with imidazolidin-2-ones proceeded selectively at $100{ }^{\circ} \mathrm{C}$ (Scheme 8). Although the ee's were modest, it nevertheless proves that enantioselective 80 reactions can be realised with group 11 metal triflates, corroborating the operation of metal-catalysed processes for these reactions.

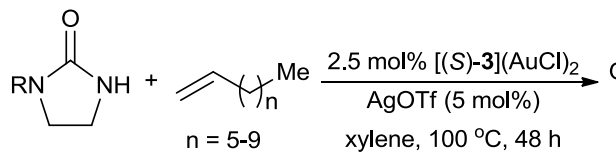

(S)-3
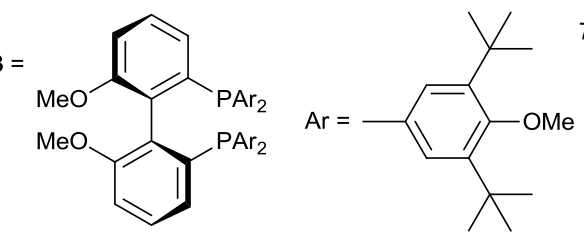<smiles>CC(C)C(C)N1CCNC1=O</smiles>
$75-89 \%$ $71-78 \%$ ee

Scheme 8 Enantioselective hydroamination of unactivated alkenes.

\section{${ }_{85}$ Outlook}


The addition of non-nucleophilic amines to unactivated alkenes converts bulk material into valuable fine chemicals (amines, amides, sulfonamies and carbamate); not only does this confer much added-value to the process, it does so with 5 great atom-economy, satisfying numerous criteria of a green chemical process. ${ }^{38}$ To date, several metal complexes have been reported to be catalytically active for these reactions under mild reaction conditions. Concurrently, strong Brønsted acids can also effect these reactions under very similar 10 reaction conditions. Evidence for both $\mathrm{H}^{+}$and metal-catalysed mechanisms exist; it is therefore important for researchers to perform the requisite control experiments and analyse their results carefully to avoid misinterpretation.

In terms of synthetic utility of these reactions, the choice of 15 catalyst is often dependent on cost, practicality and the desired reaction outcome. For most applications, Brønsted acids may be perfectly adequate, provided that the catalytic conditions can be controlled to avoid competitive side reactions. In certain cases, the conditions offered by metal 20 catalysts may be preferred, particularly for compounds containing acid-labile groups.

With the discovery of enantioselective processes, the attainment of optically active material from unactivate alkenes by the hydroamination reaction is a distinct possibility. ${ }_{25}$ However, the scope, enantioselectivity (ee's $>90 \%$ are rare) and turnover number are presently modest. For these reasons, hydroamination reactions of unactivated alkenes will remain a highly topical area of catalytic research for the foreseeable future.

\section{${ }_{30}$ Notes and references}

Department of Chemistry, Imperial College London, Exhibition Road, South Kensington, London SW7 2AZ, U.K.; E-mail:

mimi.hii@imperial.ac.uk

$35{ }^{\ddagger}$ Current affiliation: Instituto de Quimica, Universidade Estadual de Campinas, UNICAMP, C.P. 6154, CEP. 13084-971, Campinas, São Paulo, Brazil.

1. T. E. Müller, K. C. Hultzsch, M. Yus, F. Foubelo and M. Tada, 40 Chem. Rev., 2008, 108, 3795.

2. D. J. C. Constable, P. J. Dunn, J. D. Hayler, G. R. Humphrey, J. L. Leazer, R. J. Linderman, K. Lorenz, J. Manley, B. A. Pearlman, A. Wells, A. Zaks and T. Y. Zhang, Green Chem., 2007, 9, 411.

3. For example, see: (a) B. C. Ranu and S. Banerjee, Tetrahedron Lett.,

45 2007, 48, 141; (b) R. Kumar, P. Chaudhary, S. Nimesh and R. Chandra, Green Chem., 2006, 8, 356.

4. U. Dzhemilev, G. Tolstikov and R. Khusnutdinov, Russ. J. Org. Chem., 2009, 45, 957.

5. See for example: (a) C. Quinet, P. Jourdain, C. Hermans, A. Atest, I.

$50 \quad$ Lucas and I. E. Marko, Tetrahedron, 2008, 64, 1077; (b) P. HorrilloMartinez, K. C. Hultzsch, A. Gil and V. Branchadell, Eur. J. Org. Chem., 2007, 3311, and references therein.

6. M. R. Crimmin, M. Arrowsmith, A. G. M. Barrett, I. J. Casely, M. S. Hill and P. A. Procopiou, J. Am. Chem. Soc., 2009, 131, 9670.

55 7. S. Hong and T. J. Marks, Acc. Chem. Res., 2004, 37, 673.

8. P. J. Walsh, A. M. Baranger and R. G. Bergman, J. Am. Chem. Soc., 1992, 114, 1708.

9. C. Müller, R. Koch and S. Doye, Chem. Eur. J., 2008, 14, 10430.

10. M. Beller, H. Trauthwein, M. Eichberger, C. Breindl, J. Herwig, T. E. Müller and O. R. Thiel, Chem. Eur. J., 1999, 5, 1306.

11. M. Rodriguez-Zubiri, S. Anguille and J. J. Brunet, J. Mol. Catal. A: Chem., 2007, 271, 145.
12. J. E. Bäckvall, B. Åkermark and S. O. Ljunggren, J. Am. Chem. Soc., 1979, 101, 2411.

65 13. See for example: (a) C. Hahn, Chem. Eur. J., 2004, 10, 5888; (b) A. Motta, I. L. Fragala and T. J. Marks, Organometallics, 2006, 25, 5533; (c) S. Tobisch, Chem. Eur. J., 2008, 14, 8590.

14. I. Aillaud, J. Collin, J. Hannedouche and E. Schulz, Dalton Trans., 2007, 5105.

70 15. H. Qian and R. A. Widenhoefer, Org. Lett., 2005, 7, 2635.

16. D. Karshtedt, A. T. Bell and T. D. Tilley, J. Am. Chem. Soc., 2005, 127, 12640.

17. J. Zhang, C. Yang and C. He, J. Am. Chem. Soc., 2006, 128, 1798.

18. C. Brouwer and C. He, Angew. Chem. Int. Ed., 2006, 45, 1744.

75 19. X. Giner and C. Najera, Org. Lett., 2008, 10, 2919.

20. J. G. Taylor, N. Whittall and K. K. Hii, Chem. Commun., 2005, 5103.

21. J. G. Taylor, N. Whittall and K. K. Hii, Org. Lett., 2006, 8, 3561.

22. For a discussion of ethylene complexes of $\mathrm{Cu}(\mathrm{I}), \mathrm{Ag}(\mathrm{I})$ and $\mathrm{Au}(\mathrm{I})$, see: H. V. R. Dias and J. Wu, Eur. J. Inorg. Chem., 2008, 509.

80 23. J. L. McBee, A. T. Bell and T. D. Tilley, J. Am. Chem. Soc., 2008, 130, 16562.

24. X. J. Cheng, Y. Z. Xia, H. Wei, B. Xu, C. G. Zhang, Y. H. Li, G. M. Qian, X. H. Zhang, K. Li and W. Li, Eur. J. Org. Chem., 2008, 1929.

25. D. C. Rosenfeld, S. Shekhar, A. Takemiya, M. Utsunomiya and J. F. 85 Hartwig, Org. Lett., 2006, 8, 4179.

26. Z. Li, J. Zhang, C. Brouwer, C.-G. Yang, N. W. Reich and C. He, Org. Lett., 2006, 8, 4175.

27. T. C. Wabnitz, J. Q. Yu and J. B. Spencer, Chem. Eur. J., 2004, 10, 484.

90 28. Jason G. Taylor, PhD Thesis, Imperial College London, 2008.

29. J. M. Huang, C. M. Wong, F. X. Xu and T. P. Loh, Tetrahedron Lett., 2007, 48, 3375.

30. J. Michaux, V. Terrasson, S. Marque, J. Wehbe, D. Prim and J. M. Campagne, Eur. J. Org. Chem., 2007, 2601.

95 31. K. Motokura, N. Nakagiri, K. Mori, T. Mizugaki, K. Ebitani, K. Jitsukawa and K. Kaneda, Org. Lett., 2006, 8, 4617.

32. L. Yang, L. W. Xu and C. G. Xia, Tetrahedron Lett., 2008, 49, 2882.

33. G. Kovacs, G. Ujaque and A. Lledos, J. Am. Chem. Soc., 2008, 130, 853.

100 34. R. Dorta, P. Egli, F. Zurcher and A. Togni, J. Am. Chem. Soc., 1997, 119, 10857.

35. These were shown to proceed via allylpalladium(II) intermediates, see: J. F. Hartwig, Pure Appl. Chem., 2004, 76, 507 and references therein.

105 36. A. M. Johns, N. Sakai, A. Ridder and J. F. Hartwig, J. Am. Chem. Soc., 2006, 128, 9306.

37. Z. Zhang, S. D. Lee and R. A. Widenhoefer, J. Am. Chem. Soc., 2009, 131, 5372.

38. P. Anastas and J. Warner, Green Chemistry: Theory and Practice, 110 Oxford University Press, New York, 1998.

\section{Acknowledgements}

We thank the following organisations for supporting our work in this area: EPSRC, GlaxoSmithKline, Fundación Caixa 115 Galicia (Becas Postgrado 2008) and Xunta Galicia (Ángeles Alvariño). We are grateful to Professor John F. Hartwig (University of Illinois, Urbana-Champaign) for help with the revision of this manuscript. 